\title{
Innovative Spülspitze für maximale Reinigungsleistung
}

EDDY ist eine Spitze zur Schallaktivierung endodontischer Spüllösungen mit dem Airscaler. Isthmen, Seitenkanäle und apikale Ramifikationen sind ideale „Verstecke“ für Bakterien. Die mit der Kanüle eingebrachte Spüllösung kann jedoch nicht tief genug in alle Hohlräume eindringen, um alle infizierten Gewebsreste zu erfassen. Um das zu erreichen, muss die Spülflüssigkeit in kraftvolle Bewegung versetzt werden. Dazu hat der Flensburger Zahnarzt Dr. Zeppenfeld dieses neue Inst- rument entwickelt, das mit dem KnowHow von VDW München zur Marktreife gebracht wurde.

Die Polyamidspitze findet durch ihre Geometrie und besonderen Materialeigenschaften im Bereich 5000-6000 Hz die optimale Schwingungsfrequenz. Die akustischen Strömungen wirken im Zusammenspiel mit Kavitationseffekten und bewirken eine effiziente Reinigung. Eine ungewollte Nachbearbeitung der Kanalanato-

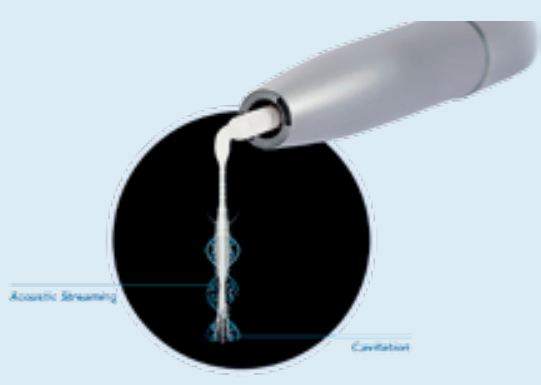

mie ist dabei ausgeschlossen, denn Polyamid ist weicher als Dentin. Das Produkt ist steril verpackt als Einmalinstrument.

\footnotetext{
Nach einer Pressemitteilung der

VDW GmbH, München

Internet: www.vdw-dental.com
} 